\title{
MORTE CEREBRAL E O ENIGMA DA MORTE
}

Brain death and the enigma of death

\author{
Maria Luiza de Castilho Anciens \\ Graduanda em Filosofia/UFRJ \\ Graduada em Psicologia pela Universidade Gama Filho - Rio de Janeiro/RJ \\ Especialização em Geriatria e Gerontologia pela UFF \\ Capacitação em Cuidados Paliativos pela UERJ \\ Membro da Sociedade Brasileira de Geriatria e Gerontologia \\ Orientadora informal para este trabalho Sarah Moura
}

RESUMO: O temor da morte sempre rodeou a humanidade que procura amenizar esse medo buscando explicações em diferentes correntes culturais, religiosas, sociais. Mas a única certeza da nossa existência é que vamos morrer e não conseguimos até hoje responder o que é a morte. A Filosofia também tenta esclarecê-la através de diferentes correntes de pensamento. Dos présocráticos aos contemporâneos a morte sempre foi uma temática filosófica, talvez mesmo o seu questionamento original. No capítulo 10, "Morte cerebral e banco de órgãos humanos: sobre a redefinição pragmática da morte” do livro “Técnica, Medicina e Ética” de Hans Jonas, ele analisa e discute de maneira profundamente impactante os critérios de morte cerebral e sua utilização para fins de doação de órgãos. A ciência evolui nos critérios da definição fisiológica da morte que era o cessar da respiração e batimentos cardíacos para ausência total das funções celebrais sempre ocasionando grande desconforto para os familiares que precisam autorizar a doação. Ao repensar os critérios de morte cerebral e sua utilização para doação de órgãos, Hans Jonas nos faz rever esse grande enigma da morte questionando até que ponto as novas tecnologias, aparentemente em favor da vida, pode nos levar a questionar os critérios éticos sobre vida, morte e nossa própria existência.

PALAVRAS-CHAVE: Morte; Morte Cerebral; Tecnologia, Hans Jonas.

\section{INTRODUÇÃO}

O temor da morte sempre rodeou a humanidade que procura amenizar esse medo buscando explicações em diferentes correntes culturais, religiosas, sociais. Mas a única certeza da nossa existência é que vamos morrer e não conseguimos até hoje responder o que é a morte. A Filosofia também tenta esclarecê-la através de diferentes correntes de pensamento. Dos présocráticos aos contemporâneos a morte sempre foi uma temática filosófica, talvez mesmo o seu questionamento original. 
Hans Jonas, no capítulo 10 do livro Técnica, Medicina e Ética, intitulado Morte cerebral e banco de órgãos humanos: sobre a redefinição pragmática da morte, analisa e discute de maneira profundamente impactante os critérios de morte cerebral e sua utilização para fins de doação de órgãos. A ciência evoluiu nos critérios da definição fisiológica da morte - que era o cessar da respiração e batimentos cardíacos - para a ausência total das funções cerebrais, sempre ocasionando grande desconforto para os familiares que precisam autorizar a doação. Ao repensar os critérios de morte cerebral e sua utilização para doação de órgãos, Hans Jonas nos faz rever esse grande enigma da morte questionando até que ponto as novas tecnologias, aparentemente em favor da vida, pode nos levar a questionar os critérios éticos sobre a vida, a morte e a nossa própria existência.

Acreditamos que o ato de se dizer doador de órgãos é muito mais emocional que racional. A ciência determinou a constatação da morte pela análise cerebral e a opção de doação de órgãos não passa pelo questionamento do que realmente é a morte cerebral. O celebro é o responsável por todas as nossas funções. Se ele parou é porque não há mais nada que possa ser feito. $\mathrm{O}$ funcionamento por aparelhos é também um avanço científico. Então porque não ser um doador? Será que a morte é realmente cerebral? Será que enquanto nosso organismo ainda funciona por aparelhos estaremos vivos? Esses foram os questionamentos que o texto de Jonas nos faz parar para refletir.

\section{Sobre morte cerebral}

Morte cerebral é o termo comumente usado, mas o correto é dizer morte encefálica. A Associação Brasileira de Transplantes de Órgãos define a morte encefálica como a “ausência total de todas as funções neurológicas em decorrência de severa agressão ou ferimento grave no cérebro e o sangue que vem do corpo e supre o cérebro é bloqueado e o cérebro morre" 1 . Portanto, morte encefálica é o termo empregado pela abrangência anatômica do sistema nervoso central envolvido.

O questionamento de Hans Jonas começou quando a comissão da Harvard Medical School publicou em 5 de agosto de 1968 essa nova definição de morte. Então numa conferência que fez sobre "Aspectos éticos de experimento com seres humanos" ele criticou duramente argumentando:

\footnotetext{
${ }^{1}$ www.abto.org.br/abtov03/dafault.aspz?mn=472\&c=015\&s-0\&friedely=entendendo-a-morte-encefálica
} 
a proposta da comissão de Harvard, ainda que seu objeto não pertencesse propriamente ao tema do experimento com sujeitos humanos: eu via nele, contudo, o perigo do abuso de tais sujeitos (pacientes) para fins médicos não muito diferente do que deveria ser evitado nas situações de experimentação (JONAS, 2013, p 230)

Jonas ainda redigiu o texto Contra a Corrente (Against the Stream) sobre o tema e foi muito contestado pelos médicos, abrindo, assim, a oportunidade de várias discussões sobre esse assunto tão difícil de ser abordado tanto na visão médica como na do senso comum de todos os pacientes e parentes envolvidos. Hans Jonas coloca seus argumentos quanto à definição de Harvard nesses dois principais tópicos:

1) Definia o coma irreversível como "morte cerebral", quando as seguintes características constam no diagnóstico: ausência de toda e qualquer atividade cerebral constatável (eletroencefalograma plano) e de toda atividade física dependente do cérebro, como respiração espontânea e reflexos;

2) Equipara a morte cerebral assim definida com a morte de todo o corpo, portanto do paciente, o que permite, para além da declaração oficial do falecimento, a interrupção de todas as ajudas oficiais de funções por meio do aparelho de respiração e quaisquer outras formas de manutenção - assim como independentemente disso (isto é, com ou sem tal interrupção) a extração de órgãos para finalidades de transplante: a condição de cadáver do corpo que permite isso começa com a determinação da morte cerebral como tal. (JONAS, 2013, p. 230-231)

Quanto ao primeiro argumento, Jonas reconhece que nem haveria necessidade de mudar os critérios de morte porque a própria igreja católica já tinha se pronunciado através da declaração do Papa Pio XII, no ano de 1957: “Quando o estado de inconsciência profunda for dado como permanente, os meios extraordinários para a manutenção da vida não são obrigatórios. Pode-se suspender seu uso e permitir ao paciente morrer" (JONAS, 2013, p 231).

Observamos que aí está o ponto principal do questionamento de Jonas: que a morte seja um processo natural. Que não se utilizem métodos invasivos na prorrogação da vida quando nada mais há a ser feito, nem antecipar a morte para quaisquer fins, mesmo os considerados humanitários. Hans alega que: “Ora, isso, seja para fins de pesquisa ou transplante, me parece ultrapassar o que uma definição (o que é o nosso trabalho) pode justificar" (JONAS, 2013, p 232).

Questionamentos tão abrangentes não podem ficar sob a tutela de uma definição da ciência. Os envolvimentos éticos, religiosos, culturais, sociais envolvidos nessa questão demandam sérias reflexões e não observamos no dia-a-dia a necessária reflexão sobre o assunto. Ninguém tem por hábito falar da própria morte ou pensar como gostaria que ela ocorresse e o que os parentes devem fazer quando esse momento chegar. Ao tentar levantar o tema as pessoas 
são tidas como mórbidas e não se discute quaisquer questões. São muito poucas as pessoas que tem um plano funeral, por exemplo.

Então temos que reconhecer que os questionamentos filosóficos podem abrir um caminho para esclarecer tão difícil questão. O que é o morrer? Até quando devemos prorrogar a vida de um paciente considerado sem condições de sobreviver? Quando devemos manter uma vida para fins de doação de órgãos? Jonas se posiciona dizendo:

Para o primeiro não necessitamos saber onde está a delimitação exata entre vida e morte - nós deixamos a natureza ultrapassá-la, onde quer que ela esteja ou que ela percorra o conjunto de espectro, caso haja mais de uma linha. Nós precisamos saber apenas como fato que o coma é irreversível, para decidir eticamente não opor resistência ao morrer. Para o segundo temos que reconhecer o limite com absoluta certeza e empregar uma definição de morte menos que máxima para cometer, em um estado possivelmente penúltimo, o que apenas o último permitiria, significa arrogar-se um conhecimento que (acredito eu) não podemos ter. Como não conhecemos o limite exato que separa a vida da morte, não nos resta nada menos que a "definição" máxima (ou melhor: determinação característica) da morte - morte cerebral, mais morte cardíaca, mais qualquer outra indicação que possa ser de interesse -;antes de que possa intervir a violência definitiva. (JONAS, 2013, p 233)

Mas, afinal, o que para nós é a morte? Com certeza se fizermos essa pergunta para uma plateia de dez, cem ou mais participantes, ouviríamos respostas diferentes de acordo a cultura, a religião, o modo de ser e pensar. Até mesmo porque essas respostas seriam de leigos e do senso comum. Será que uma definição científica da morte mudaria a opinião dessas pessoas? Observamos no texto de Hans Jonas o que nos parece uma conclusão explicativa do seu questionamento: "é a indeterminação do limite entre vida e morte, não entre sensação e falta de sensação e significa tendermos, em uma zona de incerteza essencial, mais para uma determinação máxima do que mínima da morte" (JONAS, 2013, p 233).

Ao tentar buscar para ciência a definição máxima para morte logo em seguida ele nos apresenta outros argumentos pertinentes ao tema que também deveríamos levar em consideração ao pensarmos na nossa morte e em sermos possíveis doadores. Hans nos faz pensar em questões que infelizmente a maioria da população não tem acesso que é termos um médico assistente, que nos acompanha na saúde e na doença. O direito que temos sobre nossa existência e nosso corpo. Ele diz:

Além disso, é preciso pensar também sobre o seguinte aspecto: o paciente tem que estar incondicionalmente seguro que seu médico não se tornará seu algoz e que nenhuma definição permitirá que ele venha a sê-lo. Seu direito a esta segurança é incondicional e igualmente incondicional é seu direito a seu próprio corpo com todos os seus órgãos. $\mathrm{O}$ respeito incondicional a este direito não viola qualquer outro direito. Ninguém tem, pois, um direito sobre o corpo de outra pessoa. - Para falar ainda em outro espírito, em um espírito religioso: o falecimento de uma pessoa deveria estar rodeado de piedade e protegido da exploração. (JONAS, 2013, p 234) 
O que observamos na nossa rotina com pessoas conhecidas e mesmos nossos parentes? Existe tal respeito pelo corpo humano na maioria dos hospitais que conhecemos? Os direitos dos pacientes são respeitados? Recebemos as reais informações sobre nosso estado de saúde ou de nossos familiares? Temos orientação psicológica e social nesses momentos difíceis em nossos hospitais?

No seu texto Conta a Corrente Jonas não contesta e até aceita que a nova definição quando usada para não prolongar indefinidamente a agonia do paciente e também dos familiares no caso do coma irreversível. Seu questionamento é sobre a liberdade com que a ciência se utiliza dos órgãos. Ao levantar essa discussão, ele foi convidado a passar vários dias como hóspede do Centro Médico da Universidade da Califórnia, assistindo as conferências médicas e até a frequentar as salas de cirurgias para observar a realidade do transplante de doadores e receptores, podendo fazer um trabalho mais apurado ainda sobre suas inquisições anteriores. Apesar de manter sua posição, vários médicos se tornaram seus amigos. Jonas nos diz:

Eu tinha que responder a três objeções com relação à minha primeira polêmica: que meu argumento relacionado aos "cadáveres doadores" impedia os sérios esforços médicos para salvar vidas; que eu fazia frente a fatos científicos precisos com considerações filosóficas vagas; e que desconhecia a diferença entre morte do "organismo como um todo" e a morte de "todo o organismo". (JONAS, 2013, p 237)

Vamos colocar aqui as respostas de Jonas no que se refere a parte filosófica e sintetizar seus argumentos sobre a morte.

No que se refere à acusação de "vagueza", poderia ser que ele mesmo reflita a circunstância de modo vago que meu argumento é - e eu acredito: um argumento preciso - no qual se trata da vagueza, a saber, especificamente da vagueza de um estado. Aristóteles observou certa vez que era sinal de um espírito cultivado não exigir maior exatidão (akribeia) do que o objeto permite, por exemplo, a mesma da política que na matemática. Certas formas do real do qual o espectro vida-morte talvez seja uma - podem ser em si mesmas "imprecisas" ou o saber passível de aquisição sobre as mesmas o seja. Contudo, reconhecer tal estado de coisas faz mais jus a elas do que uma definição precisa, que a elas faz violência. $\mathrm{O}$ que eu ataquei foi justamente a exatidão inadequada de uma definição e sua aplicação prática em um âmbito em si impreciso. (JONAS, 2013, p 238)

Para Hans Jonas só devemos aceitar a "morte do organismo como um todo" porque enquanto se mantém o corpo funcionando com ajuda de aparelhos para que permaneça em bom estado para doação, esse bom estado é estar vivo. Seu questionamento é instigante:

Temos, portanto, um "organismo como um todo" menos o cérebro, que é mantido em um estado parcial de vida, enquanto a máquina de respirar e outros recursos auxiliares estão funcionando. E aqui, no meu modo de entender, a 
pergunta correta não é: o paciente morreu?, mas: o que deve acontecer com ele - ainda sempre um paciente? Essa pergunta não pode, com certeza, ser respondida por meio de uma definição da morte, mas tem que ser respondida com uma "definição" do ser humano e daquilo que é uma vida humana. (JONAS, 2013, p 241)

Contestar essa a nova definição de morte foi um lançar dúvida mais uma vez no grande enigma do que é a morte. Podemos definir cientificamente com base na biologia e fisiologia, mas o enigma continua. O que é o morrer? Da mesma forma que outras perguntas sempre rodearam o ser humano como o por que morremos. A nova definição de morte encefálica produz também estudos atuais bastantes controversos. O jornal Folha de São Paulo publicou na sua edição de 18/7/2016 que no hospital de Anupam, na cidade de Rudrapur, na Índia, o cirurgião ortopédico Himanshu Bansal está conduzindo uma pesquisa com o objetivo de reverter a morte cerebral utilizando-se de células tronco e um coquetel de reprogramação celular com apoio da empresa americana de biotecnologia Bioquark. Num dos argumentos do artigo Contra a Corrente, Hans Jonas lançou uma provável premonição num dos seus argumentos sobre irreversibilidade.

Para ser mais preciso neste ponto: o "irreversível" do cessar pode ter dupla relação: com a função mesma ou apenas com a sua espontaneidade. Um cessar pode ser irreversível na perspectiva da espontaneidade, mas ainda reversível na perspectiva da atividade mesma - em cujo caso um ativador externo deve entrar em atividade no lugar do interno, isto é, no lugar da espontaneidade perdida. Este é o caso nos movimentos respiratórios e contrações cardíacas do paciente em coma (e também, recentemente, do coração artificial!). A distinção não é corriqueira. Pois, se pudéssemos fazer para um cérebro que parou de funcionar - digamos, apenas para o cerebelo - aquilo que agora podemos fazer pelo coração e pulmão, ou seja, fazê-lo trabalhar por meio da ativação externa constante (elétrica, química ou qualquer outra), o faríamos sem dúvida e não discutiríamos que a atividade resultante carece de espontaneidade: o mais importante seria atividade como tal. Esta é uma especulação puramente hipotética e, sem dúvida, irreal para sempre; mas eu duvido que um médico se sentiria legitimado a declarar como morto um paciente por causa da não espontaneidade de sua fonte cerebral, se esta pudesse ser posta em curso através de um auxílio artificial. (JONAS, 2013, p 239/240)

Acontece que essa pesquisa indiana não é aceita pelos neurocirurgiões. Se Jonas estivesse ainda entre nós, com certeza, teríamos textos instigantes sobre essas novas pesquisas. Seu argumento final é realmente para ser pensado e repensado mesmo nos dias atuais.

A linha limítrofe entre vida e morte não é conhecida com segurança e uma definição não pode substituir o saber. A suspeita de que o estado do paciente em coma sustentado artificialmente ainda é um estado residual de vida (como até há pouco também era visto de modo geral em termos médicos) não é sem fundamento. Isso significa que existe razão para a dúvida de que mesmo sem 
função cerebral o paciente que respira esteja completamente morto. Nessa situação de incomensurável não saber e de dúvida razoável, a única máxima correta para o agir consiste em inclinar-se para o lado da presumível vida. (JONAS, 2013, p 244)

Apresentar uma síntese o pensamento de Jonas a respeito da morte encefálica tem como objetivo levantar a dúvida e abrir espaço para outros questionamentos mostrando que a morte continua não só no campo da filosofia, mas no campo das ciências em geral, e até do senso comum, um grande enigma.

\section{REFLEXÕES SOBRE OS CUIDADOS PALIATIVOS}

Consideramos pertinente colocar um tema correlato à dignidade da morte que é a "nova" especialidade médica: cuidados paliativos.

Segundo a Organização Mundial de Saúde (OMS), em conceito definido em 1990 e atualizado em 2002, "cuidados paliativos consistem na assistência promovida por uma equipe multidisciplinar, que objetiva a melhoria da qualidade de vida do paciente e seus familiares, diante de uma doença que ameaça a vida, por meio da prevenção e alívio do sofrimento, da identificação precisa, avaliação impecável e tratamento de dor e demais sintomas físicos, sociais, psicológicos e espirituais (PESSINI \& BERTACHINI, 2004, p 6)

É usual que o senso comum entenda cuidados paliativos com certo preconceito por desconhecer que apalavra paliativo "deriva do latim pallium que significa manto ou cobertor. $\mathrm{Na}$ época das Cruzadas os cavaleiros recebiam esse manto - pallium - para protegê-los das intempéries do caminho na longa jornada" ${ }^{2}$. Quem está doente e sabedor ou não que sua doença não tem mais tratamento e/ou possibilidade de cura o que mais precisa é justamente de proteção, apoio para seguir seu caminho da melhor forma possível, ao lado da família, com o mínimo de sofrimento e dor.

Modernamente, essa especialidade desenvolveu-se através do incansável trabalho de Cicely Saunders (1918-2005), enfermeira inglesa que depois se formou em Assistência Social e Medicina, fundando o St. Christopher's Hospice, pioneiro no atendimento ao paciente que é considerado pelo grau de evolução da sua doença sem possibilidade de cura. Sendo comum ouvir que "não há mais nada a fazer", Cicely Saunders discordava desse prognóstico e insistia que "ainda há muito a fazer".

Esse "muito" é exatamente dar toda dignidade a essa pessoa sofredora, aliviando sua dor e preparando-a para um final de vida com o mínimo sofrimento, e participando das atividades

\footnotetext{
${ }^{2}$ casadocuidar.blogspot.com.br/p/o-que-e-cuidado-paliativo.html
} 
diárias na medida do possível, acompanhado por uma equipe multidisciplinar que o orienta, bem como a sua família.

Infelizmente, no Brasil, ainda são poucos os hospitais que têm equipe multidisciplinar específica para os cuidados paliativos. Porém, em 26 de fevereiro de 2005, foi fundado em São Paulo a Academia Nacional de Cuidados Paliativos que visa difundir e orientar os profissionais de saúde promovendo curso, congressos, debates etc... Sobre esse assunto o escritor Rubens Alves nos fala em seu livro Ostra feliz não faz pérola.

[...] A vida humana só é humana enquanto existe a possibilidade de beleza e riso. Sem beleza e sem risos a vida humana acabou. O que resta é apenas um corpo que deseja morrer. Hoje já se está dando atenção ao que se chama "terapia paliativa". "Paliativo" vem do termo pallium, capa, cobrir, esconder. A terapia paliativa entra em cena quando se sabe que a batalha está perdida. Não há mais sentido para os "recursos heróicos". Quantas quimioterapias sabidamente inúteis deixariam de ser feitas! Quanto sofrimento seria poupado! O objetivo da terapia paliativa é tornar o mais confortável possível a despedida da pessoa que vai morrer. Há de se viver bem. Há de se morrer bem. A ideia de que a medicina é uma luta contra a morte está errada. A medicina é uma luta pela vida boa, da qual a morte faz parte. (ALVES, 2008, p 268)

\section{CONCLUSÃO}

Sabemos o quanto é difícil lidar com a questão da morte e do morrer. Não deveria ser assim. A morte apenas faz parte da existência e o bem viver deve ser o ideal de todo ser para buscar um morrer bem. A decisão de doar órgãos quando declarada a morte encefálica é sempre muito difícil porque geralmente ocorre em pessoas jovens que sofrem acidentes graves. Não é uma morte esperada. Um trauma para qualquer família e como a morte não é assunto a ser debatido fica ainda mais difícil essa tomada de decisão. Conversar sobre esse assunto ajudaria muito se por acaso formos pego de surpresa pela imprevisibilidade. Acompanhar o momento da morte de um ente querido deveria ser rotina familiar, mas geralmente acontece na solidão de um CTI ou de uma enfermaria hospitalar. Elisabeth Hübler-Ross em seu livro Sobre a morte e o morrer nos fornece um refletir primoroso sobre esse momento difícil. Esse texto com certeza complementa o pensamento de Hans Jonas de que o ser humano tem o direito de ter a morte de todo corpo rodeada de ética e dignidade.

Aqueles que tiverem a força e o amor para ficar ao lado de um paciente moribundo, como silêncio que vai além de palavras, saberão que tal momento não é assustador nem doloroso, mas um cessar em paz do funcionamento do corpo. Observar a morte em paz de um ser humano faz-nos lembrar uma estrela cadente. É uma entre milhões de luzes do céu imenso, que cintila ainda por um breve momento para desaparecer para sempre na noite sem fim. Ser terapeuta de um paciente que agoniza é nos conscientizar da singularidade de cada indivíduo neste oceano imenso da humanidade. É uma tomada de consciência de nossa finitude, de nosso limitado período de vida. Poucos dentre nós vivem além dos setenta anos; ainda sim, neste curto espaço de tempo, muitos dentre 
nós criam e vivem uma biografia única, e nós mesmos tecemos a trama da história humana. (HÜBLER-ROSS, 1998, p 28)

Esse texto, com certeza, complementa o pensamento de Hans Jonas de que o ser humano tem o direito de ter a morte de todo o corpo rodeada de ética, dignidade e espiritualidade. 


\section{REFERÊNCIAS}

ALVES, Rubens. Ostra feliz não faz pérola. São Paulo: Ed. Planeta do Brasil, 2008.

JONAS, Hans. Técnica, Medicina e Ética, Capítulo 10:Morte cerebral e banco de órgãos humanos: sobre a redefinição pragmática da morte (pp 229-250). São Paulo: Paulus, 2013.

KÜBER-ROSS, Elisabeth. Sobre a morte e o morrer. São Paulo: Martins Fontes, 1998. Tradução de Paulo Menezes, $8^{a}$ edição.

PESSINE, L \& BERTACHINE, L. (orgs). Humanização e Cuidados Paliativos. São Paulo: Centro Universitário São Camilo\& Edições Loyola, 2004, $2^{a}$ edição.

www.casadocuidar.blogspot.com.br/p/o-que-e-cuidado-paliativo.html

www.abto.org.br $/$ abtov03/dafault.aspz?mn $=472 \& c=015 \& s-0 \&$ friedely $=$ entendendo-a-morteencefálica

www.folha.vol.com.br/ciencia/2016/07/1792720-indianos-tentam-reverter-morte-cerebral.shtml 